\title{
Solar-Powered Charging Networks for Electric Vehicles
}

\author{
Larry Erickson *(D) and Stephanie Ma*(D) \\ Tim Taylor Department of Chemical Engineering, Kansas State University, Manhattan, KS 66506, USA \\ * Correspondence: lerick@ksu.edu (L.E.); slma@ksu.edu (S.M.)
}

check for

updates

Citation: Erickson, L.; Ma, S. Solar-Powered Charging Networks for Electric Vehicles. Energies 2021, 14, 966. https://doi.org/10.3390/ en14040966

Academic Editor: Kari Tammi

Received: 11 January 2021

Accepted: 8 February 2021

Published: 12 February 2021

Publisher's Note: MDPI stays neutral with regard to jurisdictional claims in published maps and institutional affiliations.

\section{Copyright: (c) 2021 by the authors.} Licensee MDPI, Basel, Switzerland. This article is an open access article distributed under the terms and conditions of the Creative Commons Attribution (CC BY) license (https:// creativecommons.org/licenses/by/ $4.0 /)$.

\begin{abstract}
The cost of solar-generated electricity and battery costs have been decreasing significantly. These developments can be combined to introduce solar-powered charging networks with demand management prices (DMP) to enable electric vehicle (EV) customers to help utilities to manage renewable energy. As solar-generated electricity becomes the cheapest source of power, the need to increase demand for electricity during the day can be met by charging EVs at an attractive DMP in parking lots with solar panels and charging stations that are connected to the electrical grid. The demand for electricity can be managed and controlled by the utility with the goal of increasing demand for power as needed so that all electricity that is generated can be sold. The proposal is to introduce a new DMP rate that is only implemented when the utility wants to increase demand and sell power at this low rate in order to make full use of the supply. As utilities strive to reach $100 \%$ renewable electrical power to serve a society transported by EVs, cooperative plans to make good use of batteries in EVs for managing the electrical grid will become more important.
\end{abstract}

Keywords: solar; wind; electric vehicles; Paris Agreement; sustainable development; supply and demand; electricity

\section{Introduction}

During the last 10 years, there has been great progress in advancing sustainable development [1-43]. In 2015, the Paris Agreement on Climate Change was adopted by the Parties to the United Nations Framework Convention on Climate Change [3], and it came into force in November 2016 [2]. The Sustainable Development Goals were adopted in 2015 at the United Nations [2,4]. Reducing greenhouse gas emissions (GHG), improving air quality, implementing affordable and sustainable energy, and increasing the quality of life are some of the important goals that are related to this work [2,4]. The Paris Agreement's goal is net-zero emissions, such that concentrations of carbon dioxide and other GHGs become stable, with emissions being balanced by processes that decrease concentrations [2,3]. Many people would like to encourage a race to net-zero emissions, with many organizations, cities, and countries aiming to achieve the goal by 2040 .

The progress in transportation powered by electricity has been rapid, with millions of electric vehicles (EVs) in use presently. The largest numbers of EVs are two-wheel bicycles and scooters; however, passenger cars, buses, and trucks have increased in popularity as new models have been introduced. The rapid decrease in the cost of batteries has made EVs more competitive [2]. Many people are using EVs to improve quality of life by reducing their emissions [2,20,21].

In 2019, more than $41 \%$ of electricity generated in Kansas was from wind energy because prices for electricity from wind have decreased to approximately USD 30/MWh ( 3 cents $/ \mathrm{kWh}$ ) after a federal incentive is included [5]. Because of its low cost, wind energy is one of the best ways to generate electricity and reduce carbon emissions in Kansas.

The cost of electricity generated with solar energy has decreased significantly and it is now very competitive. Because of research and development, the projected price in 2022 is less than USD 40/MWh and less than USD 30/MWh with the tax credit [6,7]. In addition, prices are expected to continue to decrease as new developments are implemented. 
Between 2021 and 2040, the amount of solar-generated electricity is expected to increase and become a major source of electrical power in the United States $[6,7]$. The quality of wind and solar resources varies with location; however, there are many sites in the world where wind and/or solar are competitive and are being used to generate electricity.

Both wind and solar have natural features that impact the amount of electricity that is generated at a given time. Thus, the utility must manage electric power with an uncertain quantity supplied by wind and solar. Under these conditions, demand management becomes more important for the utility because of clouds and variations in wind velocity. One way for the utility to be involved in demand management is by generating and supplying electricity through solar-powered charging networks for EVs.

Combustion emissions must be reduced for both electricity generation and transportation to achieve the goals of the Paris Agreement and the Sustainable Development Goals $[2-4,26]$. It is important for EVs to be charged with renewable electricity. Demand management alternatives must be identified and developed to optimize electricity production and distribution with wind and solar energy.

In Section 2 below, the concept of managed charging of EVs in parking lots with solar panels and charging stations is described. Section 3 introduces the concept of dispatchable demand to balance the supply and demand of renewable electrical power. In Sections 4-6, the benefits of dispatchable demand are presented. Locations for parking lots with utilitymanaged EV charging are the subject of Section 7. The future for dispatchable demand management is considered in Section 8, and global goals are presented in Section 9. Conclusions are in Section 10.

\section{Parking Lots with Solar Panels and Charging Stations}

There are many parking lots with solar panels and charging equipment for EVs $[1,8,9]$. The city of Santa Cruz, California constructed a large-scale solar project on municipal parking lots and began using them for shaded parking and EV charging in 2013. The project saves the city around USD 73,000 annually and reduces greenhouse gas emissions by around 200 tons/year [8].

As shown in Figures 1 and 2, in any parking lot that receives sunlight, solar panels and EV charging equipment can be added to provide convenient charging while EVs are parked and not in use. In Kansas, the estimated electricity generated from a parking space shaded by a $3 \mathrm{~m} \times 8 \mathrm{~m}$ solar panel array is approximately $16 \mathrm{kWh} /$ day-which would provide $4 \mathrm{~kW}$ of power at peak power times [1]. Thus, 3.2 billion $\mathrm{kWh} /$ day could be generated with 200 million shaded parking spaces [1].

The concept of managed charging has been introduced because of the need for electric utilities to balance supply and demand of electrical power [2,10]. If a utility has control of EV charging in a network of parking lots with solar panels and level one or level two chargers connected to EVs, it can increase demand by supplying power to a portion of the EVs at a demand management price (DMP) that is good for the customer and the utility. This price would be less than the time-of-use (TOU) rate and more than the utility could get if it sold the electricity into the power grid. The DMP would be expected to be used when the supply from wind and solar creates excess power that could best be managed by increasing demand and selling power to EV customers who want to purchase electricity at the DMP.

Many owners of battery electric vehicles (BEVs) have batteries with more than $80 \mathrm{kWh}$ of capacity, while they may use less than $15 \mathrm{kWh}$ for their normal daily driving. If they have more than $40 \mathrm{kWh}$ of energy when they arrive at the parking lot, they can plug their $\mathrm{BEV}$ in and request charging at the DMP if it becomes available. If a customer needs to have the battery charged, the TOU rate can be requested. If a DMP rate is available, an EV customer may attempt to purchase all needed power at the DMP by regularly requesting charging at the DMP and only purchasing electricity at the higher rate when the energy level in the battery needs to be increased. 


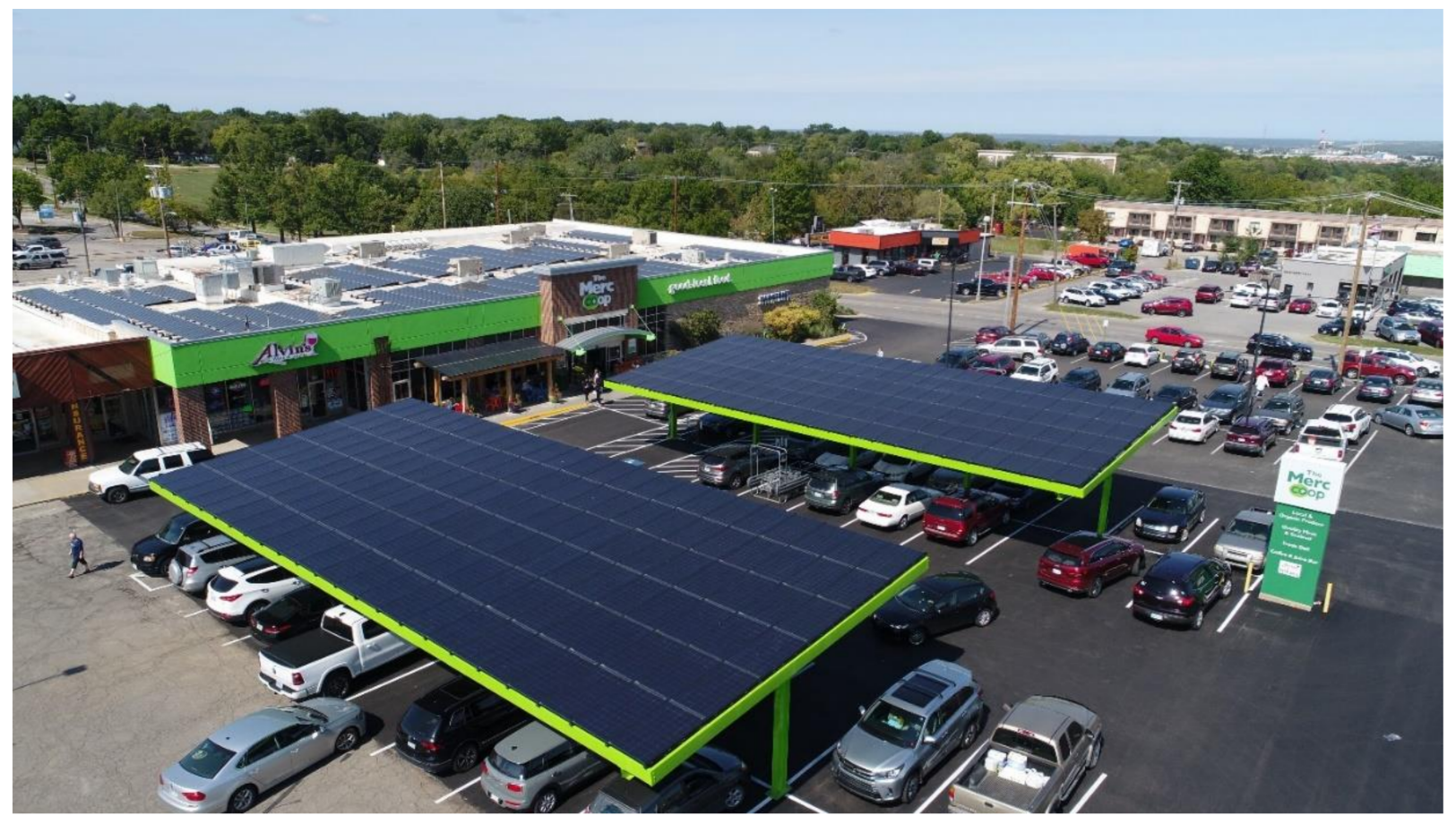

Figure 1. Solar-powered charging infrastructure at Lawrence Community Mercantile.

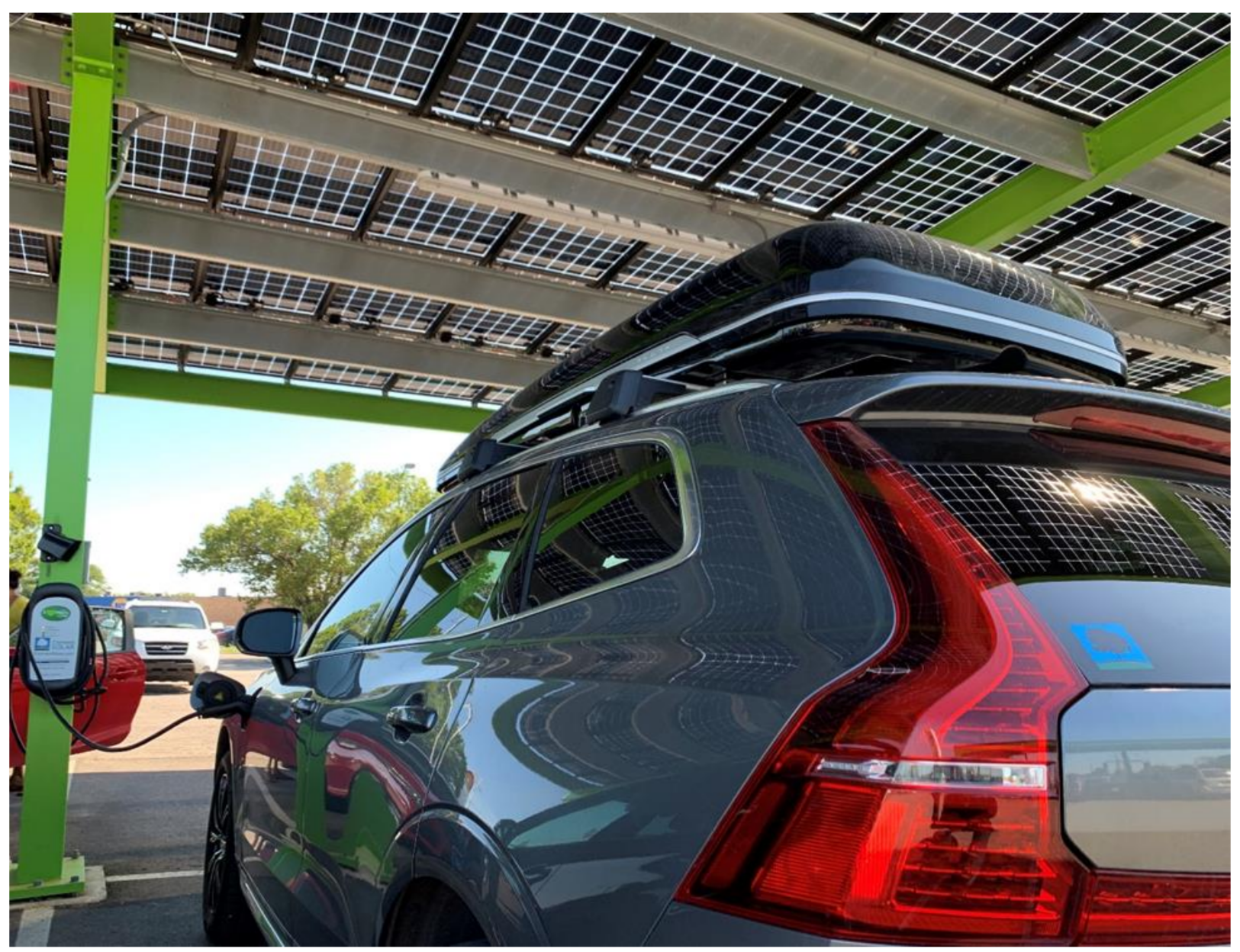

Figure 2. EV charging at Lawrence Community Mercantile. 
The ownership of parking lots with solar panels and charging infrastructure may depend on laws that impact public utilities and the sale of electrical power. Public utilities are approved to sell electricity, but the DMP and demand management plan may need to be approved in some locations. Cooperative efforts may be best in some cases where the electric utility works cooperatively with other partners to develop and operate the sites.

Customers with EVs may need to pay for parking as well as for the electrical power that is provided. Funding can also come from advertisements, employers, government, and merchants.

In the United States, there are many locations that may be developed for balancing supply and demand of electrical power based on an estimated 200 million parking spaces that might have solar panels installed [1]. In Kansas, many parking lots have good features for adding solar panels and charging infrastructure. The need to manage demand in Kansas is expected to become important as solar- and wind-generated electricity continue to decrease in cost compared to other alternatives and because of efforts to reduce carbon dioxide emissions. Kansas has many days with good solar and wind resources (being among the top five states in terms of total wind energy generation and among the 10 sunniest states in the country) and shade provided by solar panels is very beneficial on hot summer days [41]. In Kansas, public utilities are regulated and approval would be needed for a utility to establish and operate solar-powered charging networks for EVs with control of EV charging at a DMP.

\section{Electric Power Management}

The concept of dispatchable demand is introduced in this part of the paper. In the management of the electrical grid, demand for power is adjusted to meet supply by controlling power flow to the EVs connected to the solar-powered charging network, where EVs are charged as needed to balance supply and demand based on the supply of renewable power. The solar-powered charging network is operated such that the grid operator manages the dispatchable demand by changing power flow to the EVs, such that all of the electric power from wind and solar generation is delivered to the grid and used efficiently and effectively.

As the portion of power generated by wind and solar increases, there will be more times when demand needs to increase to equal supply. The utility has the option of storing electrical energy in batteries and using other energy storage systems, such as pumping water, to a higher elevation. Time-of-use (TOU) prices for electricity have the potential to help achieve a good balance between supply and demand by shifting demand to match supply [40]. The DMP with utility management of demand has benefits for the utility because wind and solar supply change as the wind velocity changes and clouds impact solar generation. If the utility has a large network of parking lots with BEVs that are available to be charged, it will be easier to balance supply and demand. Using the BEVs for demand management does not require an investment in batteries for energy storage by the utility. With modern smart grids and control system technology, the utility can manage demand effectively at a reasonable cost. Recording the amount of energy delivered is possible with modern technology, also. The utility would be expected to use the network of connected EVs as one of several options to help balance supply and demand [2,10,11].

Demand management is an important topic and considered in many publications $[2,19,23,27,28,32-36]$. Most of the past work has been on managing peak power demand. There is smart grid literature related to time-of-use prices and real-time prices [2,37]. The case where EV customers respond to prices for electricity and receive power is different from the dispatchable demand case above, where the grid operator supplies power to EVs as needed to balance supply and demand. The optimization of EV charging and energy storage in batteries as part of smart grid management is an active area of research [19]. 


\section{Economic Benefits}

\subsection{Immediate Benefits}

Solar-powered charging networks for EVs with control of EV charging at the DMP would have economic benefits for EV customers, the utility, and those who receive electricity from the utility.

- The utility benefits by being able to use the network to help manage supply and demand for its electrical power.

- The network allows the utility to increase demand for electric power when the supply is available and to sell electricity at a price that is better than other alternatives.

- Under conditions where wind and solar energy are the cheapest alternatives to generate electricity, it is beneficial to produce and deliver power to customers in this cost-effective way; that is, the utility operates more efficiently because of the network of EVs and the opportunity to manage demand.

- Those who purchase power from the utility benefit from the reduced cost for electricity that is associated with the more efficient operation that is possible because of the managed charging of EVs.

- Since the solar-powered charging network has locations where parking is needed, transmission costs associated with the network are low.

This also reduces GHG emissions, which would improve air quality and benefit everyone. Additional economic value can be estimated using the social cost of carbon and the tons of carbon dioxide that are not emitted [12,13,31].

\subsection{The Social Value of Carbon (Long-Term Benefits)}

New York's Department of Environmental Conservation plans to have a zero-carbonemissions electricity sector by 2040 and $70 \%$ renewable energy generation by 2030 [38]. To guide them in this endeavor, they have established social values for the following greenhouse gases [39]:

- Carbon dioxide: USD 125/ton

- Methane: USD 2782/ton

- Nitrous oxide: USD 44,727/ton

These numbers were calculated using a "damages approach" (which quantifies the societal damages of GHG emissions) by:

1. Estimating emissions for all relevant GHGs;

2. Considering global damages;

3. Using the most recent data (atmospheric GHG concentrations, economics, and other relevant information) available;

4. Applying a "discount rate" that "reflects the rate at which society as a whole is willing to trade off a value received at one point in time (e.g., today) with a value received at another point in time (e.g., the future)".

This is the guideline outlined by the 2019 Climate Leadership and Community Protection Act for use by state agencies [31].

There are significant savings associated with when and where EVs are charged $[24,25]$. The economic benefits of using batteries in EVs to deliver power to the grid are an active area of research [19]. There are many ways to integrate wind- and solar-generated electricity, $\mathrm{EVs}$, and battery storage into the smart grid, and many of these advances have economic value $[28,29,32]$.

\section{Environmental Benefits}

Both wind- and solar-generated electricity are clean and free of emissions. The goals of reaching steady-state concentrations of GHGs and improving air quality by reducing combustion processes are global and are being advanced through the United Nations. The solar-powered charging networks for EVs with control of EV charging at the DMP would have environmental benefits by increasing the use of electricity generated by wind 
and solar. The DMP for EV charging would encourage the purchase and use of EVs, which would reduce combustion by decreasing the use of internal combustion engines. The availability of a network of parking lots with EV charging would result in more EV purchases because of reduced concerns about finding locations to charge batteries [25].

The benefits of better air quality in large cities are among the most significant issues because more than 3 million people die each year because of poor ambient air quality [2]. The heat island associated with cities occurs because of solar radiation onto surfaces that increase in temperature and because of heat generated by internal combustion engines on roads and streets. Solar panels in parking lots convert some of the solar radiation into electricity and EVs are very efficient; therefore, the heat island effect is reduced [1]. There are many papers that address the environmental benefits associated with the transition to electricity generated with wind and solar energy, EVs for transportation, and battery storage for the smart grid $[1,2,26,30]$.

\section{Social Benefits}

The shade provided in parking lots by solar panels is an important benefit because temperature in an EV can increase significantly when it sits in the sun, especially in a state "with about the same solar potential as Florida" [1,41]. Shade is beneficial to the preservation of the paint on the car and when it is charged on a hot day. Improved air quality associated with reduced combustion emissions has both social and health benefits. The convenience of having EV charging in parking lots with a choice of TOU and DMP rates is a social benefit. All of society would benefit from the reduced GHG emissions.

Research has shown that air quality may impact emotional health [14]. By analyzing the geo-tagged tweets of Chinese citizens with a machine-learning sentiment algorithm (that scored the happiness of the tweets) before merging those results with $\mathrm{PM}_{2.5}$ concentration data, Sigi Zheng and co-authors found that "on polluted days, people [were] more likely to engage in impulsive and risky behavior that they may later regret", suggesting that the "high levels of air pollution in China may contribute to the urban population's reported low level of happiness" [14,15].

The health benefits associated with the transition to clean renewable energy and EVs have significant social value, and this is an important consideration as policy decisions are made $[1-4,26]$. The large number of parking lots with solar panels and charging stations will be convenient for those who use them to charge their EVs.

\section{Locations}

One of the best locations for solar-powered charging networks for EVs with DMP is where customers work because the EV may be there for most of the day. Public schools, colleges, and universities have large parking lots and the duration of parking is appropriate. There are airport parking lots where EVs may be parked for longer periods that may be used for DMP charging.

There are parking lots associated with hospitals, shopping centers, museums, and other similar facilities where there are both employees and customers. The employees would benefit by having a DMP charging network at these locations.

\section{Future Planning}

There are presently many locations where solar panels and charge stations have been installed in parking lots; however, the concept of demand-managed charging with DMP is a more recent development which will become more important in the future as the portion of wind- and solar-generated electricity increases $[2,10]$. These renewable sources of electricity are expected to become more competitive as their costs continue to decrease [20]. Between 2021 and 2040, the need will increase for solar-powered charging networks for EVs with control of EV charging at a DMP. The number of EVs in service is increasing and this is important for demand-managed charging. 
The estimated future size of dispatchable demand in the US with solar-powered charging networks is approximately 100 million EVs with an average of $10 \mathrm{kWh}$ added to each per day or approximately one billion $\mathrm{kWh} /$ day in 2040. At that time, electricity from wind and solar energy will be the cheapest option in many locations, which will make demand management much more important than it is now $[2,19,32-36]$. Shortly after President Biden signed an executive order to attain a "carbon pollution-free electricity sector no later than 2035; and clean ... zero-emission vehicles for Federal, State, local and Tribal government fleets", General Motors publicly announced their plan to only sell electric vehicles by 2035 [42,43]. This accentuates the urgency of managing carbonless electricity, and the method repeatedly proven to be most effective is to make demand dispatchable through the methods mentioned above [1-3,27-30,32-37].

\section{Global Goals}

Solar-powered charging networks for EVs with control of EV charging at a DMP may be installed in many countries and used with all types of EVs. Many countries may benefit by producing and marketing basic EVs that provide good, useful transportation at much lower cost compared to EVs that are popular in the USA. The two-wheel EVs have provided excellent transportation for many people. The technology is simple and it can be used in any country.

Solar radiation and wind are available in many locations to provide affordable and sustainable electrical power. Electricity generated by wind and solar energy and EVs for transportation are important aspects of many plans to reduce GHG emissions to meet the goals of the Paris Agreement. Demand-managed charging of EVs can help many countries to meet their Sustainable Development Goals [2].

Several goals are presented in Table 1. The most important challenge is to reduce GHG emissions to reach net-zero emissions with constant GHG concentrations in the atmosphere. One expected benefit of net-zero emissions is much better air quality in large cities. These goals and the other UN Sustainable Development Goals should have high priority as decisions are made to improve quality of life for everyone.

Table 1. Global goals related to Paris Agreement and Sustainable Development Goals.

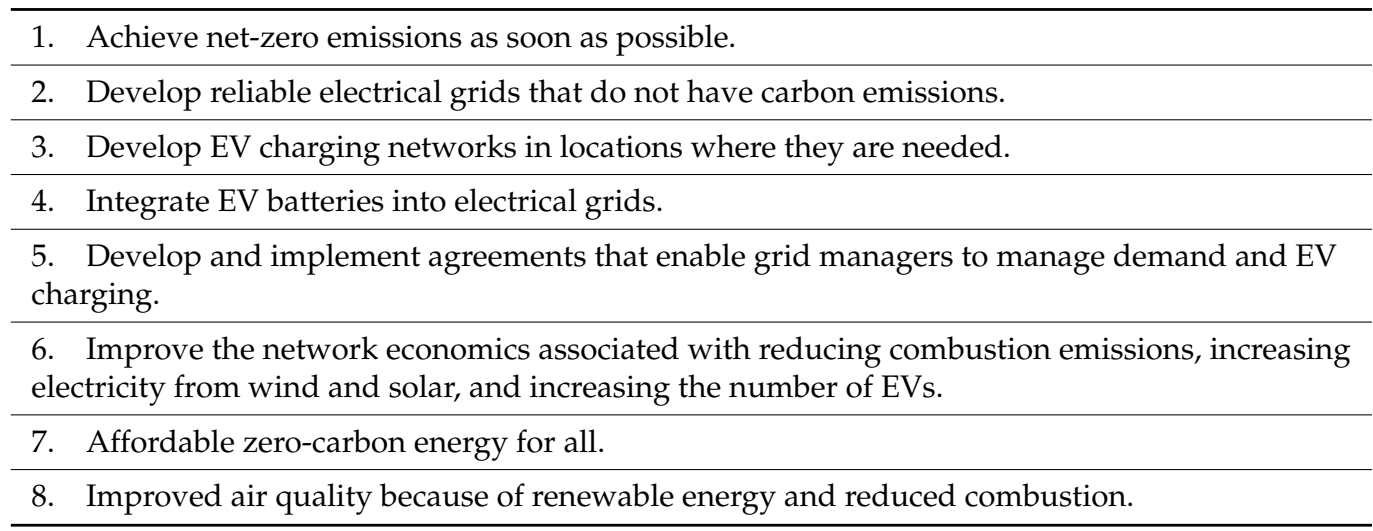

Improving air quality in large cities has great value for society because the global cost of present-day poor air quality is approximately USD 4 trillion/year [2]. The impact of poor air quality on health is shown in Table 2, where deaths associated with $\mathrm{PM}_{2.5}$ particulate pollution are reported [2]. Recently, there has been some progress in lowering $\mathrm{PM}_{2.5}$ concentrations in China, as shown in Table 3. In India in 2019, the annual average population-weighted mean $\mathrm{PM}_{2.5}$ concentration was 91.7 micrograms per cubic meter and deaths due to poor ambient air quality were 72 per 100,000 people [16]. In the United States and many other parts of the world, ozone concentrations exceed regulatory values, and the social cost of ozone pollution is significant [18]. 
Table 2. Median urban annual concentration of $\mathrm{PM}_{2.5}$ and deaths per year per 100,000 people associated with ambient air pollution [2].

\begin{tabular}{ccc}
\hline Country & $\begin{array}{c}\text { PM }_{2.5} \text { Concentration } \\
\text { Micrograms/Cubic Meter }\end{array}$ & Deaths/100,000 \\
\hline China & 59 & 76 \\
Egypt & 101 & 51 \\
India & 66 & 49 \\
Japan & 13 & 24 \\
Netherlands & 15 & 24 \\
Nigeria & 38 & 28 \\
Turkey & 35 & 44 \\
United Kingdom & 12 & 26 \\
United States of America & 8 & 12 \\
\hline
\end{tabular}

Table 3. Average annual $\mathrm{PM}_{2.5}$ concentrations measured near the US embassy building in Beijing, China [17].

\begin{tabular}{cc}
\hline Year & $\mathbf{P M}_{\mathbf{2 . 5}}$ Concentration Micrograms/Cubic Meter \\
\hline 2009 & 102 \\
\hline 2010 & 104 \\
\hline 2011 & 99 \\
\hline 2012 & 91 \\
\hline 2013 & 102 \\
\hline 2014 & 98 \\
\hline 2015 & 83 \\
\hline 2016 & 73 \\
\hline 2017 & 59 \\
\hline 2018 & 51 \\
\hline 2019 & 43 \\
\hline
\end{tabular}

There are significant economic, environmental, and social benefits associated with improving air quality in major cities of the world by implementing the ideas in this work and transitioning to electricity generated with wind and solar energy, EVs (including electric buses), and solar-powered charging networks with DMP and dispatchable demand. This would also reduce greenhouse gas emissions. There are expected health benefits as well.

\section{Conclusions}

Wind- and solar-generated electricity, EVs, and energy storage in batteries can be used to advance sustainable development, reduce GHG emissions, and improve air quality. Solar-powered charging networks may be constructed and used with dispatchable demand and DMP by electric utilities to improve demand management when large quantities of renewable power are being supplied. Demand management is becoming more important as the percentage of power generated with renewable energy increases. Globally, trillions of dollars can be saved as costs of solar-generated electricity decrease, solar-powered charging networks with DMP are introduced and used, electric-powered transportation increases toward $100 \%$, net-zero GHG emissions are approached, and $\mathrm{PM}_{2.5}$ concentrations in large cities decrease toward 10 micrograms/cubic meter.

Author Contributions: Both authors made substantial contributions to the preparation of this manuscript. Both authors have read and agreed to the published version of the manuscript. 
Funding: This research received no external funding.

Institutional Review Board Statement: Not applicable.

Informed Consent Statement: Not applicable.

Data Availability Statement: No new data was generated in this study.

Acknowledgments: This research has been supported financially by Kansas State University. We thank Danita Deters for her help with the manuscript and Cromwell Solar from Lawrence, Kansas for permission to use Figures 1 and 2.

Conflicts of Interest: The authors have no conflict of interest.

Biographical Information: Larry E. Erickson is professor of chemical engineering at Kansas State University. He received his B.S.Ch.E. in 1960 and PhD in 1964 from K-State, and he became a member of the faculty in 1964. He is an author of the two books that appear as References [1,2] in this manuscript. He is a fellow of the American Institute of Chemical Engineers. Stephanie Ma is an undergraduate student majoring in chemical engineering at Kansas State University. Her professional interests include environmental engineering. Renewable energy is one of her research interests.

\section{References}

1. Erickson, L.E.; Robinson, J.; Brase, G.; Cutsor, J. (Eds.) Solar Powered Charging Infrastructure for Electric Vehicles: A Sustainable Development; CRC Press: Boca Raton, FL, USA, 2017.

2. Erickson, L.E.; Brase, G. Reducing Greenhouse Gas Emissions and Improving Air Quality: Two Interrelated Global Challenges; CRC Press: Boca Raton, FL, USA, 2020.

3. UNFCCC. Paris Agreement. United Nations Framework Convention on Climate Change; United Nations: New York, NY, USA, 2015.

4. UN. Transforming Our World: The 2030 Agenda for Sustainable Development; United Nations: New York, NY, USA, 2015.

5. Erickson, L.E. Kansas' Transition to Renewable Energy is Speeding Up. Kansas Reflector. 26 September 2020. Available online: kansasreflector.com/ (accessed on 4 January 2021).

6. Sukunta, M. Annual Energy Outlook 2020; U.S. Energy Information Administration: Washington, DC, USA, 2020. Available online: https: / / www.eia.gov/ outlooks/aeo/ (accessed on 4 January 2021).

7. Levelized Cost and Levelized Avoided Cost of New Generation Resources in the Annual Energy Outlook 2020; U.S. Energy Information Administration: Washington, DC, USA, 2020. Available online: eia.gov (accessed on 4 January 2021).

8. Santa Cruz. Go Solar Santa Cruz. City of Santa Cruz: Santa Cruz, CA, USA. Available online: cityofsantacruz.com/gosolarsc (accessed on 4 January 2021).

9. Matasci, S. Solar Canopy Installations Bring Shade and Clean Energy to Your Parking Lot; Energy Sage: Boston, MA, USA, 2017; Available online: news.energysage.com (accessed on 4 January 2021).

10. Douris, C. How Electric Vehicles Can Support the Grid; Lexington Institute: Arlington, VA, USA, 2018. Available online: lexingtoninstitute.org (accessed on 4 January 2021).

11. Fitzgerald, G.; Nelder, C.; Newcomb, J. Electric Vehicles as Distributed Energy Resources; Rocky Mountain Institute: Basalt, CO, USA, 2018. Available online: https://rmi.org/wp-content/uploads/2017/04/RMI_Electric_Vehicles_as_DERs_Final_V2.pdf (accessed on 4 January 2021).

12. Social Cost of Carbon; GAO-20-254; U.S. Government Accountability Office: Washington, DC, USA, 2020.

13. Paul, I.; Howard, P.; Schwartz, J.A. The Social Cost of Greenhouse Gases and State Policy; Institute for Policy Integrity, New York School of Law: New York, NY, USA, 2017.

14. Zheng, S.; Wang, J.; Sun, C.; Zhang, X.; Khan, M.E. Air Pollution Lowers Chinese Urbanite's Expressed Happiness on Social Media. Nat. Hum. Behav. 2019, 3, 237-243. [CrossRef] [PubMed]

15. Knight, H. In China, a Link between Happiness and Air Quality; MIT News, Massachusetts Institute of Technology: Cambridge, MA, USA, 2019. Available online: news.mit.edu (accessed on 4 January 2021).

16. India State-Level Disease Burden Initiative Air Pollution Collaborators. Health and Economic Impact of Air Pollution in the States of India: The Global Burden of Disease Study 2019. Lancet Planet Health 2019, 5, E25-E38.

17. Textor, C. Average Annual PM2.5 Air Pollution Levels in Beijing, China between 2009 and 2019; Statista: Hamburg, Germany, 2020. Available online: www.statista.com (accessed on 4 January 2021).

18. Erickson, L.E.; Newmark, G.L.; Higgins, M.J.; Wang, Z. Nitrogen Oxides and Ozone in Urban Air: A Review of 50 Plus Years of Progress. Environ. Prog. Sustain. Energy 2020, 39, e13484. [CrossRef]

19. Faia, R.; Soares, J.; Vale, Z.; Corchado, J.M. An Optimization Model for Energy Community Costs Minimization Considering a Local Electricity Market between Prosumers and Electric Vehicles. Electronics 2021, 10, 129. [CrossRef]

20. Berckmans, G.; Messagie, M.; Smekens, J.; Omar, N.; Vanhaverbeke, L.; Van Mierlo, J. Cost Projection of State of the Art Lithium-Ion Batteries for Electric Vehicles Up to 2030. Energies 2017, 10, 1314. [CrossRef]

21. Penisa, X.N.; Castro, M.T.; Pascasio, J.D.A.; Esparcia, E.A.; Schmidt, O.; Ocon, J.D. Projecting the Price of Lithium-Ion NMC Battery Packs Using a Multifactor Learning Curve Model. Energies 2020, 13, 5276. [CrossRef] 
22. Paniyil, P.; Singh, R.; Asif, A.; Powar, V.; Bedi, G.; Kimsey, J. Transformative and Disruptive Role of Local Direct Current Power Networks in Power and Transportation Sectors. Electron. Energetics 2019, 32, 387-402. [CrossRef]

23. Aoun, A.; Ibrahim, H.; Ghandour, M.; Ilinca, A. Supply Side Management vs. Demand Side Management of a Residential Microgrid Equipped with an Electric Vehicle in a Dual Tariff Scheme. Energies 2019, 12, 4351. [CrossRef]

24. Borlaug, B.; Salisbury, S.; Gerdes, M.; Muratori, M. Levelized Cost of Charging Electric Vehicles in the United States. Joule 2020, 4, 1470-1485. [CrossRef]

25. Greene, D.L.; Kontou, E.; Borlaug, B.; Brooker, A.; Muratori, M. Public charging infrastructure for plug-in electric vehicles: What is it worth? Transp. Res. Part D Transp. Environ. 2020, 78, 102182. [CrossRef]

26. Óhaiseadha, C.; Quinn, G.; Connolly, R.; Connolly, M.; Soon, W. Energy and Climate Policy-An Evaluation of Global Climate Change Expenditure 2011-2018. Energies 2020, 13, 4839. [CrossRef]

27. Miyazaki, K.; Kobayashi, K.; Azuma, S.-I.; Yamaguchi, N.; Yamashita, Y. Design and Value Evaluation of Demand Response Based on Model Predictive Control. IEEE Trans. Ind. Inform. 2019, 15, 4809-4818. Available online: ieeexplore.ieee.org (accessed on 21 January 2021). [CrossRef]

28. Conteh, A.; Lotfy, M.E.; Adewuyi, O.B.; Mandal, P.; Takahashi, H.; Senjyu, T. Demand Response Economic Assessment with the Integration of Renewable Energy for Developing Electricity Markets. Sustainability 2020, 12, 2653. [CrossRef]

29. Gan, L.; Jiang, P.; Lev, B.; Zhou, X. Balancing of supply and demand of renewable energy power system: A review and bibliometric analysis. Sustain. Futur. 2020. [CrossRef]

30. Miller, I.; Arbabzadeh, M.; Gençer, E. Hourly Power Grid Variations, Electric Vehicle Charging Patterns, and Operating Emissions. Environ. Sci. Technol. 2020, 54, 16071-16085. [CrossRef] [PubMed]

31. Cuomo, A.M.; Seggos, B. Establishing a Value of Carbon: Guidelines for Use by State Agencies; New York State Department of Environmental Conservation: New York, NY, USA, 2019.

32. Bronski, P.; Dyson, M.; Lehrman, M.; Mandel, J.; Morris, J.; Palazzi, T.; Ramirez, S.; Touati, H. The Economics of Demand Flexibility: How "Flexiwatts" Create Quantifiable Value for Customers and the Grid; Rocky Mountain Institute: Boulder, CO, USA, 2015. Available online: https://rmi.org/wp-content/uploads/2017/05/RMI_Document_Repository_Public-Reprts_ RMI-TheEconomicsofDemandFlexibilityFullReport.pdf (accessed on 21 January 2021).

33. Goldenberg, C.; Dyson, M.; Masters, H. Demand Flexibility: The Key to Enabling a Low-Cost, Low-Carbon Grid; Rocky Mountain Institute Insight Brief: New York, NY, USA; Boulder, CO, USA, 2018. Available online: https://rmi.org/wp-content/uploads/20 18/02/Insight_Brief_Demand_Flexibility_2018.pdf (accessed on 21 January 2021).

34. Hodge, C. Aligning PEV Charging Times with Electricity Supply and Demand; National Renewable Energy Laboratory: Golden, CO, USA, 2017. Available online: https: / / www.nrel.gov / docs/fy17osti/68623.pdf (accessed on 21 January 2021).

35. Hale, E.; Bird, L.; Padmanabhan, R.; Volpi, C. Potential Roles for Demand Response in High-Growth Electric Systems with Increasing Shares of Renewable Generation; National Renewable Energy Laboratory: Golden, CO, USA, 2018. Available online: www.nrel.gov (accessed on 21 January 2021).

36. Hand, M.M.; Baldwin, S.; DeMeo, E.; Reilly, J.M.; Mai, T.; Arent, D.; Porro, G.; Meshek, M.; Sandor, D. Renewable Electricity Futures Study; National Renewable Energy Laboratory: Golden, CO, USA, 2012. Available online: https://www.nrel.gov/docs/fy12osti/ 52409-1.pdf (accessed on 21 January 2021).

37. Hove, A.; Sandalow, D. Electric Vehicle Charging in China and the United States; Columbia School of International and Public Affairs, Center on Global Energy Policy: New York, NY, USA, 2019.

38. Buckner, M.; Endres, J.; Fattey, C.; Hecker, M.; Holden, E.; Logan, M.; Main, S.; Malcomb, C.; McKernan, J.; Meosky, P.; et al. New York Department of Environmental Conservation Releases "Value of Carbon" Guidance that Could Spur More Aggressive Climate Policies; Hodgson Russ LLP: New York, NY, USA, 2021.

39. Updated Values for Carbon Dioxide, Methane, and Nitrous Oxide to Inform New York's Actions to Reduce Emissions; New York State Department of Environmental Conservation: New York, NY, USA, 2020. Available online: dec.ny.gov (accessed on 31 January 2021).

40. Bazilian, M.; Miller, M.; Detchon, R.; Liebreich, M.; Blyth, W.; Futch, M.; Modi, V.; Jones, L.; Barkett, B.; Howells, M.; et al. Accelerating the Global Transformation to 21st Century Power Systems. Electr. J. 2013. [CrossRef]

41. Kansas State Profile and Energy Estimates; U.S. Energy Information Administration: Washington, DC, USA, 2020. Available online: https: / / www.eia.gov/state/?sid=KS (accessed on 31 January 2021).

42. Executive Order on Tackling the Climate Crisis at Home and Abroad. WH.gov Briefing Room, Presidential Actions. 2021. Available online: whitehouse.gov (accessed on 31 January 2021).

43. Wayland, M. General Motors Plans to Exclusively Offer Electric Vehicles by 2035; CNBC: Englewood Cliffs, NJ, USA, 2021. Available online: cnbc.com (accessed on 31 January 2021). 